\title{
ANALISIS PENGARUH FASHION INVOLVEMENT TERHADAP IMPULSE BUYING MELALUI HEDONIC VALUE DI H\&M STORE PAKUWON MALL SURABAYA
}

\author{
Angela Natalie A. ${ }^{1}$, Edwin Japarianto ${ }^{{ }^{*}}$ \\ ${ }^{1}$ Program Studi Manajemen, Fakultaas Ekonomi, Universitas Kristen Petra \\ Jl. Siwanalkerto 121-131, Surabaya 60236 \\ * Penulis korespondensi; E-mail: edwinj@petra.ac.id
}

\begin{abstract}
Abstrak: Penelitian ini bertujuan untuk mengetahui pengaruh dari Fashion Involvement terhadap Impulse Buying melalui Hedonic Value yang dilakukan oleh konsumen fashion di H \& M Store Pakuwon Mall Surabaya. Penelitian ini dilaksanakan dengan menyebarkan kuesioner kepada 100 responden pelanggan H \& M di Pakuwon Mall Surabaya.Teknik analisa yang digunakan adalah teknik analisis kuantitatif dengan metode path analisis. Hasil penelitian ini menunjukan bahwa fashion involvement berpengaruh secara positif dan signifikan terhadap hedonic value, fashion involvement berpengaruh secara positif dan signifikan terhadap impulse buying, dan hedonic value berpengaruh secara berpengaruh secara positif dan signifikan terhadap impulse buying, serta menunjukan bahwa hedonic value sebagai variable intervening tidak berhasil memediasi hubungan antara fashion involvement dan impulse buying.
\end{abstract}

Kata kunci: Fashion involvement, hedonic value, impulse buying.

\begin{abstract}
The purpose of this research is to analyze the impact between fashion involvement and Impulse buying by hedonic value that consument does in H \& M Pakuwon Mall store in Surabaya. This study is causally using a quantitative approach. The collection of data in a structured way and using statistical methods as the analysis of data. The method used is a survey method that opens a structured questionnaire. This research conducted by spreading 100 questionnaires to customers of $H$ \& M Pakuwon Mall Surabaya. Analysis quantitative with path analysis method will be the technique method to analyze this research. The results of this study indicate fashion involvement influence positively and significantly related to hedonic value, fashion involvement affect positively and significantly related to impulse buying, hedonic value in a positive and significant impact on impulse buying. However, the results of this study indicates that the hedonic value cannot be a mediator of variable intervening between fashion involvement and impulse buying.
\end{abstract}

Keywords: Fashion involvement, hedonic value, impulse buying

\section{PENDAHULUAN}

Pada zaman sekarang ini pengaruh perkembangan era globalisasi dan modernisasi dirasakan oleh sebagian besar masyarakat di Indonesia. Kesadaran masyarakat akan pentingnya fashion juga merupakan salah satu penyebab perkembangan tersebut karena masyarakat lebih mudah untuk mendapatkan informasi seputar perkembangan fashion internasional, hal tersebut menghasilkan perubahan masyarakat dalam memilih gaya berpakaian mereka. Tingkat kesadaran akan fashion yang tinggi memicu munculnya Fashion Involvement dalam gaya hidup masyarakat. Setiap konsumen berbeda sesuai dengan tingkat keterlibatan mereka dalam konsumsi fashion, konsumen dengan tingkat keterlibatan fashion yang tinggi menganggap konsumsi pakaian haruslah relevan dengan sense diri mereka dan dapat menjadi pemimpin opini di antara rekan-rekan mereka (Goldsmith et al., 1999; (O'Cass, 2000); Douglas et al., 1976). Lebih spesifiknya, $F a$ shion Involvement dapat meningkatkan kecenderungan untuk pembelian produk fashion (Han et al., 1991; (Park, Kim, \& Forney, 2006).
Involvement telah memainkan peran penting dalam literatur tentang pemasaran. Telah ditemukan bahwa Fashion Involvement mempengaruhi keadaan emosi konsumen selama berbelanja (Park et al., 2006) dan secara positif memengaruhi Impulse Buying. Didukung pula oleh hasil penelitian sebelumnya bahwa Fashion Involvement memiliki dampak positif pada perilaku pembelian impulsif berbasis fashion, maka Fashion Involvement dapat digunakan sebagai ukuran keterlibatan pelanggan terhadap produk fashion untuk mengetahui hubungan antara fashion involvement terhadap impulse buying pelanggan.

Meskipun pembelian semacam itu tidak disengaja, tetapi tetap dianggap memuaskan kebutuhan tertentu (Hausman, 2000). Impulse Buying terkait dengan hedonisme (Rook and Hoch, 1985). Konsumen melaporkan bahwa mereka merasa lebih baik setelah pembelian impulsif (Rook, 1987), bahkan mengalami rasa dihargai dan konsumen cenderung memuaskan hasrat hedonis mereka melalui pembelian impulsif (Hausman, 2000). Kecenderungan konsumsi hedonik secara positif mempengaruhi dengan baik kecenderungan Impuls Buying Fashion, temuan ini didu- 
kung oleh penelitian sebelumnya (Park et al., 2006). Menurut Park, Kim dan Forney (2006), Hedonic shopping value memainkan peran penting dalam impulse buying. Oleh karena itu, sering kali konsumen mengalami impulse buying ketika didorong oleh keinginan hedonis atau sebab lain di luar alasan ekonomi, sebagai contoh seperti disebabkan oleh rasa senang, fantasi, sosial, atau pengaruh emosional. Dalam studi pada mahasiswa, Park et al. (2006) menemukan bahwa siswa memenuhi kebutuhan hedonis mereka melalui pembelian impuls yang berorientasi pada mode. Liapati (2015), menemukan bahwa impulsivitas afektif konsumen memiliki dampak positif yang kuat pada perilaku impulse buying.

Melihat dari hasil penelitian sebelumnya tersebut dapat diketahui adanya hubungan antara $\mathrm{Fa}$ shion Involvement terhadap Impulse Buying dalam Hedonic Value dalam konsumsi produk fashion seseorang. Pemahaman tersebut memerlukan penelitian lebih lanjut terhadap sebuah objek yang spesifik agar dapat menghasilkan sebuah strategi marketing yang optimal dikemudian hari terutama bagi perusahaan ritel fashion internasional yang masuk kedalam pasar dalam negri tepatnya di Surabaya.

Berdasarkan kuesioner yang telah disebarkan kepada 34 responden usia remaja 17 - 25 tahun berlokasi di Surabaya yang memiliki Fashion Involvement dan memiliki pengalaman berbelanja di H\&M Pakuwon Mall Surabaya, terdapat hasil yang mendukung pemilihan objek penelitian di H\&M Pakuwon Mall Surabaya karena objek penelitian tersebut mencangkup seluruh variable yang diteliti yaitu Fashion Involvement, Hedonic Value dan Impulse Buying.

Tidak hanya berkaca dari hasil kuesioner tersebut, penulis pun melakukan observasi lapangan dan hasil yang saya temukan secara umum konsumen yang melakukan impulse buying karena tingginya ketertarikan akan model serta kualitas dari produk fashion yang disediakan, keinginan untuk memiliki produk fashion tersebut dan kepentingan agar mereka dapat menarik perhatian karena menggunakan produk fashion terkini dari H\&M. Model dari fashion H\&M sendiri tidak hanya mengikuti fashion terkini melainkan fashion dengan gaya basic yang dapat digunakan sepanjang masa. Untuk kualitas dari produk itu sendiri sangat sesuai dengan nominal yang relatif terjangkau untuk dikeluarkan oleh konsumen $\mathrm{H} \& \mathrm{M}$ serta menggunakan bahan yang aman dan nyaman.

Kesimpulan dari data diatas adalah konsumen dari H\&M memiliki kecenderungan kesadaran akan fashion dan melakukan pembelian secara impulse buying atau tidak terencana sebelumnya melalui hedonic value yang dimiliki para konsumen tersebut yang disebabkan oleh beberapa faktor. Berdasarkan hal tersebut, maka penelitian ini akan membahas mengenai analisis pengaruh Fashion Involvement terhadap Impulse Buying melalui Hedonic Value dengan pemilihan objek penelitian yaitu toko ritel fashion H\&M di Pakuwon Mall Surabaya.

\section{LANDASAN TEORI}

\section{Fashion Involvement}

Involvement memiliki arti sebuah ikatan atau keterlibatan antara seseorang dengan sebuah objek yang didasari oleh kebutuhan, nilai dan juga ketertarikan serta keuntungan yang dapat mereka dapatkan dari objek tersebut (berupa merek, iklan atau bahkan situasi pembeli). Sedangkan arti Fashion Involvement menurut beberapa ahli merupakan tingkat keterlibatan konsumen dengan fashion dimana mereka cenderung mengutamakan pakaian sebagai bagian sentral dalam kehidupan mereka karena fashion dianggapnya sebagai tanggung jawab sosial dan mereka cenderung menggunakan fashion mode terbaru. (O'Cass, 2004, p. 870); (Park et al., 2006).

Fashion Involvement memiliki 5 dimensi utama yang dikonseptualisasikan dari tingkat kesadaran rendah hingga tertinggi menurut (Douglas, 1976):

1. Fashion innovativeness and time of purchase

2. Fashion interpersonal communication

3. Fashion interest

4. Fashion eligibility

5. Fashion awareness and reaction to fashion trends

\section{Impulse Buying}

Impulse buying adalah perilaku pembelian yang mendadak, menarik, dan hedonis kompleks di mana proses keputusan impuls tersebut tanpa pertimbangan yang bijaksana dan tanpa mementingkan informasi alternatif dan pilihan (Bayley dan Nancarrow, 1998). Beberapa macam dari barang-barang pelanggan berasal dari pembelian tidak terencana (impulse buying), barang-barang yang dilaporkan paling sering dibeli adalah pakaian, perhiasan ataupun aksesoris yang dekat dengan diri sendiri dan mendukung penampilan (Park et al.,2006).

Menurut penelitian Engel et al. (1995:156) dalam Japarianto (2011), pembelian berdasar impulse memiliki satu atau lebih karakteristik berikut ini:

(1) Spontanitas.

(2) Kekuatan, kompulsi, dan intensitas.

(3) Kegairahan dan Stimulasi.

(4) Ketidakpedulian akan akibat.

\section{Hedonic Value}

Hedonic value berasal dari kesenangan dan kenikmatan pengalaman dalam proses belanja (Holbrook 
\& Hirschman, 1982). Maka dapat dilihat bahwa hedonic value mencerminkan potensi hiburan dan nilai emosional dari belanja itu sendiri. Kegiatan seperti melihat-lihat display atau cuci mata dan menjelajahi rak-rak yang dipamerkan, mengobrol dengan staf dan bersenang-senang seperti menemukan barang murah membuat perjalanan belanja menjadi sebuah petualangan. Jadi meskipun belanja tidak menghasilkan pembelian yang sebenarnya, hedonic value masih dapat diperoleh dari banyak aspek proses belanja (Markin et al., 1976).

Menurut (Arnold \& Reynolds, 2003) terdapat beberapa dimensi dalam hedonic value:

1) Adventure shopping,

2) Social shopping,

3) Gratification shopping,

4) Idea shopping,

5) Role shopping,

6) Value shopping

\section{Model Penelitian}

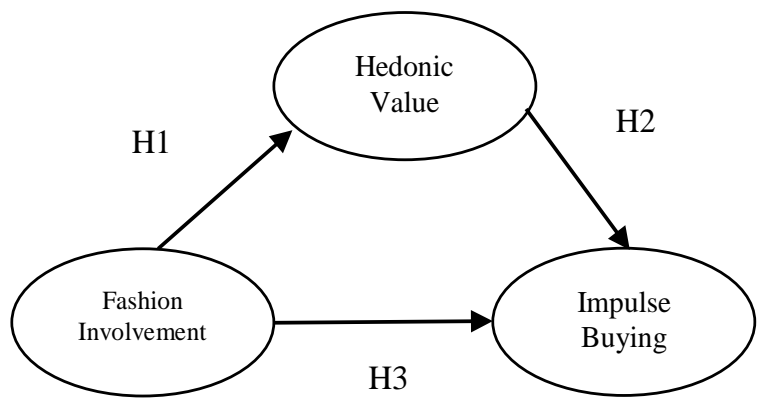

Gambar 1. Model Penelitian

\section{Hipotesa}

H1: Fashion involvement berhubungan positif terhadap hedonic value konsumen di H\&M Pakuwon Mall Surabaya

H2: Fashion involvement berhubungan positif terhadap impulse buying konsumen di H\&M Pakuwon Mall Surabaya

H3: Hedonic value berhubungan positif terhadap impulse buying konsumen di H\&M Pakuwon Mall Surabaya

\section{METODE PENELITIAN}

\section{Populasi}

Menurut (Churchill, 2005; Parasuraman, 1991) populasi merupakan gabungan elemen yang memiliki berbagai karakteristik yang serupa, dan mencakup semesta untuk kepentingan masalah riset pemasaran. Populasi adalah wilayah generalisasi yang terdiri dari obyek atau subyek yang dimana mempunyai kualitas dan karakteristik tertentu yang diterapkan oleh peneliti untuk dipelajari dan kemudian ditarik kesimpulannya. Populasi dalam penelitian ini adalah pelanggan H\&M store di Pakuwon Mall Surabaya.

\section{Sampel}

Sampel merupakan unsur-unsur dari jumlah dan karakteristik yang dimiliki oleh populasi dimana peneliti ingin melakukan kajian pemasaran (Wahdi, 2011). Dalam penelitian ini, peneliti akan menggunakan teknik nonprobability sampling, dimana semua populasi tidak memiliki peluang yang sama untuk menjadi responden dan pengambilan sampel didasarkan pada pertimbangan peneliti (Churchill, 2005) (Wahdi, 2011). Sampel diambil/terpilih karena ada di H\&M Pakuwon Mall Surabaya dan sedang berbelanja merek $\mathrm{H} \& \mathrm{M}$.

\section{Definisi Operasional Variabel}

\section{Fashion Involvement (XI)}

Fashion Involvement merupakan tingkat keterlibatan konsumen dengan fashion dimana mereka cenderung mengutamakan pakaian sebagai bagian sentral dalam kehidupan mereka karena fashion dianggapnya sebagai tanggung jawab sosial dan mereka cenderung menggunakan fashion mode terbaru.

Dimensi dari Fashion involvement adalah sebagai berikut:

- Xi. Saya mengutamakan menggunakan mode Fashion yang inovatif.

- Xi. Saat H\&M mengeluarkan mode pakaian terbaru di season ini, saya langsung membeli pakaian tersebut di awal season.

- Xi. Saya sering memberikan informasi seputar fashion di H\&M kepada orang sekitar saya.

- Xi. Saya memiliki ketertarikan yang tinggi jika membahas seputar fashion produksi $\mathrm{H} \& \mathrm{M}$

- Xi. Saya memiliki pengetahuan yang banyak seputar fashion seperti mode yang terbaru, bahan yang nyaman, tren fashion sepanjang masa dan banyak lainnya.

- Xi. Saya selalu mengikuti semua perubahan mode meskipun saya tidak selalu mencoba untuk berpakaian sesuai dengan perubahan fashion ini

Impulse Buying $\left(\mathrm{Y}_{1}\right)$

Impulse Buying adalah perilaku pembelian yang tidak direncanakan sebelumnya dan tanpa pertimbangan yang mendalam karena didorong oleh kondisi emosi seseorang tanpa memikirkan kemungkinan adanya akibat negatif yang biasanya barang tersebut terdiri dari barang dengan harga yang terjangkau dan 
berukuran kecil. Dimensi dari Impulse Buying sebagai berikut:

- Yi. Saya sering melakukan pembelian secara tibatiba di H\&M Pakuwon Mall Surabaya.

- Yi. Saya tidak berpikir panjang pada saat berbelanja barang fashion di H\&M Pakuwon Mall Surabaya.

- Yi. Saya berambisi mendapatkan produk fashion tersebut dan mengesampingkan hal lainnya.

- Yi. Saya merasa bersemangat jika berbelanja produk H\&M.

- Yi. Saya cenderung tidak memikirkan resiko jika saya berbelanja produk H\&M.

\section{Hedonic Value $\left(\mathrm{Z}_{1}\right)$}

Hedonic value merupakan sebuah nilai yang dirasakan oleh konsumen yang disebabkan oleh pengalaman proses berbelanja yang menjadikan sebuah hiburan bagi konsumen walaupun tidak menghasilkan pembelian yang sebenarnya.

Dimensi variabel Hedonic Value dalam penelitian ini yaitu:

- Zi. Dengan berbelanja Saya merasakan memiliki sensasi tersendiri dan Saya merasa di dunia Saya sendiri.

- Zi. Belanja adalah cara untuk menghabiskan waktu bersama teman dan / atau anggota keluarga.

- Zi. Ketika suasana hati saya "Bad mood", saya pergi berbelanja untuk membuat saya merasa lebih baik.

- Zi. Saya pergi berbelanja ketika saya ingin memanjakan diri saya dengan sesuatu yang Special.

- Zi. Saya merasa baik ketika saya membeli barangbarang untuk orang-orang spesial dalam hidup saya.

- Zi. Saya menikmati berbelanja untuk teman dan keluarga saya.

\section{ALAT ANALISA}

\section{Path Analysis}

Statistik pada model path analysis dilakukan dengan menggunakan metode partial least square. Partial Least Square (PLS) adalah bagian dari struktural equation marketing (SEM). PLS merupakan teknik yang banyak diminati karena tidak membutuhkan distribusi normal atau dapat dikatakan sebuah penelitian dengan jumlah sampel yang sedikit. Salah satu kelebihan PLS-SEM adalah mampu menangani model yang kompleks dengan multiple variabel independen dan dependen dengan banyak indikator, dapat digunakan pada sampel dengan jumlah kecil, dan data distribusi yang condong (Abdillah \& Hartono, 2015).

\section{T-test}

Di dalam penelitian ini terdapat variabel intervening yaitu penghubung antara variabel dependen dan variabel independen. Pengujian hipotesis mediasi (variabel intervening) dapat dilakukan dengan prosedur $t$-test. Pengujian $t$-test digunakan untuk mendapatkan nilai $t$-statistik yang diperlukan apabila peneliti ingin melakukan uji hipotesis, sehingga peneliti dapat mengatakan pengaruh sebuah variabel dapat dikatakan memiliki pengaruh yang signifikan atau tidak. $T$ test dilakukan dengan menggunakan metode bootstrapping.

Metode bootstrapping adalah suatu proses pengujian re-sampling yang dilakukan oleh sistem komputer untuk mengukur akurasi pada sample estimate. Bootstraping digunakan untuk mengukur akurasi pada sample. Apabila nilai bootstrap lebih dari (>) 1.96 maka dinyatakan bahwa variabel tersebut memiliki pengaruh yang signifikan sedangkan apabila nilai bootstrap lebih rendah $(<)$ dari 1.96 , maka dinyatakan pengaruh variabel tersebut lemah (Abdillah \& Hartono, 2015).

\section{Statistik deskriptif}

Statistik deskriptif digunakan untuk menyajikan data secara deskriptif yang menggambarkan karakteristik responden serta berbagai jawaban responden agar mampu digunakan sebagai kesimpulan dari hasil kuesioner yang telah disebarkan selama penelitian ini.

\section{ANALISA DAN PEMBAHASAN}

\section{Analisa Deskriptif}

Tabel 1.CrosstabulationPengeluaran Belanja dan Pembelian Tiba-tiba

\begin{tabular}{|c|c|c|c|c|c|c|c|}
\hline & & \multicolumn{4}{|c|}{ IBPembelianTibaTiba } & \multirow[b]{2}{*}{ SS } & \multirow[b]{2}{*}{ Total } \\
\hline & & STS & TS & $\mathrm{N}$ & $S$ & & \\
\hline \multirow[t]{4}{*}{ PengeluaranBelanja } & Rp. 100.000 -Rp. 250.000 & 0 & 1 & 2 & 8 & 3 & 14 \\
\hline & Rp. $250.001-$ Rp. 500.000 & 1 & 3 & 11 & 19 & 23 & 57 \\
\hline & Rp. $500.001-$ Rp. 1.000 .000 & 1 & 0 & 1 & 9 & 10 & 21 \\
\hline & Diatas Rp. 1.000 .001 & 0 & 0 & 2 & 2 & 4 & 8 \\
\hline Total & & 2 & 4 & 16 & 38 & 40 & 100 \\
\hline
\end{tabular}

Pada tabel 1, variable Impulse buying membahas tentang bagaimana konsumen H\&M melakukan pembelian yang tidak direncanakan sebelumnya karena adanya dorongan emosi. Jika dilihat dari tabel diatas responden yang memiliki lebih banyak uang untuk berbelanja lebih cenderung melakukan pembelian secara tiba-tiba dibandingkan dengan responden yang memiliki budget atau uang untuk berbelanja.

Pada tabel 2, variable yang sama yaitu Impulse Buying menunjukkan bahwa semakin sedikit lama waktu konsumen H\&M berbelanja maka konsumen 
semakin tidak berpikir panjang dalam berbelanja produk tersebut dibandingkan dengan konsumen yang menghabiskan lebih banyak waktu untuk berbelanja.

Tabel 2. Crosstabulation Lama Waktu Berbelanja dengan Tidak Berpikir Panjang

\begin{tabular}{|c|c|c|c|c|c|c|c|}
\hline & & & IBTidake & pikirPan & & & \\
\hline & & STS & TS & $\mathrm{N}$ & S & SS & Total \\
\hline LamaWaktu & 30 menit - 1 jam & 1 & 16 & 11 & 15 & 16 & 59 \\
\hline & 1-2jam & 6 & 3 & 7 & 10 & 8 & 34 \\
\hline & $2-3 \mathrm{jam}$ & 0 & 2 & 3 & 1 & 1 & 7 \\
\hline Total & & 7 & 21 & 21 & 26 & 25 & 100 \\
\hline
\end{tabular}

Tabel 3. Crosstabulation Pengeluaran Belanja dan Memperbaiki Suasana Hati

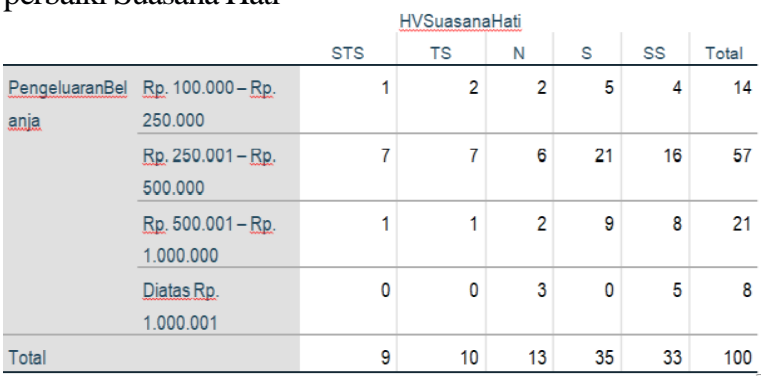

Pada tabel 3, variabel Hedonic Value yang membahas tentang sebuah nilai yang dirasakan oleh konsumen dimana nilai tersebut disebabkan oleh pengalaman proses berbelanja seseorang yang menjadikan berbelanja sebagai sebuah hiburan bagi orang tersebut. Jika melihat dari tabel diatas dapat dilihat bahwa semakin besar nominal pembelanjaan yang dikeluarkanatau daya beli konsumen maka semakin tinggi nilai berbelanja untuk memperbaiki suasana hati.

Tabel 4. Crosstabulation Pengeluaran Belanja dengan Berbelanja untuk Memanjakan Diri

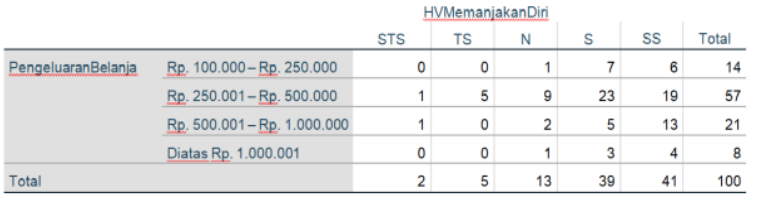

Pada tabel 4, dengan variable yang sama yaitu Hedonic value dapat dilihat bahwa semakin besar nominal konsumen dalam berbelanja produk $\mathrm{H} \& \mathrm{M}$ maka semakin besar pula hedonic value khususnya dalam berbelanja untuk memanjakan diri mereka yang dirasakan oleh konsumen tersebut.

\section{Evaluasi Path Coefficient dan Coefficient of deter- mination}

Pada analisa path coefficient ini telah terbukti bahwa hedonic value bukan merupakan variabel intervening yang dimana memperlemah hubungan antara fashion involvement dengan impulse buying sebesar 0.078 yang dimana merupakan hasil perkalian antara 0.380 dan 0.206 . Hubungan fashion involvement terhadap impulse buying secara langsung menunjukan angka 0.339 dimana angka yang menunjukan hubungan secara langsung ini lebih besar daripada menggunakan hedonic value sebagai variable intervening.

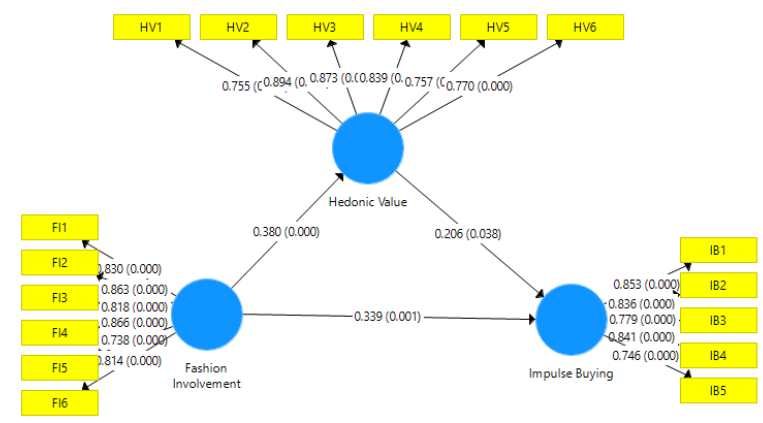

Gambar 2. Path Coefficient dan Coefficient of Determination

Nilai coefficient of determination $\left(\mathrm{R}^{2}\right)$ yang di dalam gambar menunjukan bahwa fashion involvement mampu menerangkan hedonic value dan impulse buying sebesar 0.195 dan 0.136 secara berurutan. Hasil dari Nilai coefficient of determination $\left(\mathrm{R}^{2}\right)$ lebih kecil dari 0.5 sehingga menunjukan informasi antar tiap tiap variabel yang tidak terlalu kuat.

\section{T-statistic}

T-statistic pada pengaruh fashion involvement terhadap hedonic value menunjukan 4.470 yang artinya fashion involvement berpengaruh signifikan terhadap hedonic value.T-statistic pada pengaruh fashion involvemen terhadap impulse buying menunjukan 3.417 yang artinya fashion involvement berpengaruh signifikan terhadap impulse buying.T-statistic pada hedonic value terhadap impulse buying menunjukan 2.080 yang artinya hedonic value berpengaruh signifikan terhadap impulse buying.

\section{PEMBAHASAN}

\section{Fashion Involvement terhadapHedonic Value}

Penelitian ini memiliki hasil bahwa Fashion involvement pada pembelanjaan produk fashion di H\&M Pakuwon Mall Surabaya memiliki pengaruh terhadap Hedonic value secara signifikan dengan nilai uji $T$-statistic $>1.96$ yaitu 4.470 .

Hasil terebut yang menyatakan bahwa Fashion Involvement memiliki pengaruh yang signifikan terhadap Hedonic Value mendukung hasil penelitian 
yang telah dilakukan sebelumnya oleh Park et al. (2006) yang menemukan bahwa siswa bidang tekstil memenuhi kebutuhan hedonis mereka melalui pembelian impuls yang berorientasi pada Fashion karena adanya sebuah ikatan atau keterikatan pada mode tersebut, Dengan adanya Fashion Involvement seseorang akan merasakan hedonic value karena dengan selama proses hedonic tersebut berlangsung seseorang akan merasa terhibur dan mendapatkan banyak informasi seputar fashion. Semakin tinggi Fashion Involvement seseorang maka semakin tinggi pula Hedonic Value dirasakan orang tersebut terutama pada proses berbelanja produk fashion .

H\&M sendiri telah melakukan banyak upaya untuk meningkatkan hedonic value pada penyediaan produk fashion kepada para konsumennya. Terbukti dengan hasil yang menyatakan H\&M dapat memberikan sebuah hedonic value dalam berbelanja sebagai aktivitas untuk menghabiskan waktu bersama dengan keluarga dan teman, memperbaiki suasana hati, memanjakan diri, serta berbelanja barang untuk diberikan kepada orang yang special bagi konsumen yang memiliki tingkat keterlibatan terhadap fashion tersebut. Maka dapat disimpulkan H\&M telah berhasil memberikan sebuah hedonic value kepada konsumen yang memiliki fashion involvement.

\section{Fashion Involvement terhadap Impulse Buying}

Penelitian ini memiliki hasil bahwa Fashion involvement pada pembelanjaan produk fashion di H\&M Pakuwon Mall Surabaya memiliki pengaruh terhadap Impulse buying secara signifikan dengan nilai uji $T$-statistic $>1.96$ yaitu 3.417 .

Hasil kuesioner tersebut mendukung pernyataan (MacInnis, D.J., 1987) yang menyatakan bahwa tingkat keterlibatan terhadap fashion juga memiliki korelasi yang tinggi dengan perilaku pembelian impulsif, sehingga konsumen akan melakukan pembelian impulsif terhadap pakaian dengan model-model dan desain terbaru. Para responden yang memiliki keterikatan pada fashion tersebut cenderung melakukan pembelian impulse selama berada di H\&M store, sebagian besar dari para responden melakukan pembelian secara tiba-tiba dengan tidak berpikir panjang terlebih dahulu sebelum membeli produk fashion yang disediakan oleh H\&M, serta mengesampingkan hal diluar belanja produk fashion tersebut dan secara tidak langsung para responden cenderung tidak memikirkan resiko dalam berbelanja produk tersebut.

Dari hasil tersebut maka dapat disimpulkan bahwa H\&M telah berhasil mendorong konsumennya melakukan pembelian impulse dengan menyediakan produk fashion brand tersebut.

\section{Hedonic Value terhadap Impulse Buying}

Penelitian ini memiliki hasil bahwa Hedonic value pada pembelanjaan produk fashion di H\&M Pakuwon Mall Surabaya memiliki pengaruh terhadap Impulse buying secara signifikan dengan nilai uji $T$ statistic $>1.96$ yaitu 2.080 .

Penelitian ini mendukung pernyataan bahwa perilaku impulse buying didorong oleh tujuan mencari hedonistik atau kesenangan yang menyebabkan konsumen mengalami keinginan untuk membeli atau memiliki sebuah produk (Virvilaitơ \& Saladieno, 2012). Para responden yang merasakan hedonic value ketika berbelanja produk fashion di H\&M store tersebut cenderung terdorong untuk melakukan pembelian secara impulse, dibuktikan dari hasil kuesioner yang menyatakan bahwa mereka yang merasakan berbelanja dapat memberikan nilai bagi mereka dimana hal tersebut disebabkan oleh pengalaman proses berbelanja yang menjadikan sebuah hiburan bagi responden terdorong melakukan pembelian impulse karena mereka secara tiba-tiba berbelanja tanpa merencanakannya terlebih dahulu serta mengesampingkan hal lain di luar belanja dan tidak memikirkan resiko serta tidak berpikir panjang dahulu.

Maka dapat disimpulkan bahwa dengan melakukan pembelian impul tersebut maka semakin tinggi nilai yang responden rasakan dalam proses berbelanja di H\&M Pakuwon Mall Surabaya, dan hal ini menunjukkan arti bahwa H\&M telah berhasil memberikan hedonic value yang lebih lagi kepada para konsumen karena jika seseorang masuk ke H\&M store, konsumen tersebut cenderung melakukan pembelian impul.

\section{KESIMPULAN DAN SARAN}

\section{Kesimpulan}

Berdasarkan hasil penelitian mengenai Analisis Pengaruh Fashion Involvement Terhadap Impulse Buying Melalui Hedonic Valuedi H\&M Store Pakuwon Mall Surabaya maka diperoleh hasil bahwa Fashion Involvement konsumen produk fashion H\&M Pakuwon Mall Surabaya berpengaruh secara signifikan terhadap Impulse buying melaluiHedonic value. Dimana Hedonic Value yang dirasakan oleh konsumen produk fashion H\&M Pakuwon Mall Surabaya meningkatkan Impulse Buying

\section{Saran}

Untuk H\&M Pakuwon Mall Surabaya:

1. Meningkatkan kualitas layanan

Denga memiliki karyawan yang tidak hanya memahami seputar promo yang disediakan oleh 
H\&M melainkan karyawan yang memiliki fashion involvement dan siap untuk membantu para konsumen yang kesulitan menentukan pilihan tersebut.

2. Mengeluarkan tren fashion original by $\mathrm{H} \& \mathrm{M}$

Mengeluarkan fashion yang original design by H\&M agar dapat semakin meningkatkan Hedonic Value serta Impulse Buying konsumen yang memiliki keterikatan pada fashion tersebut dan memperkuat brand $\mathrm{H} \& \mathrm{M}$ ini sendiri karena dapat selalu membuat tren fashion baru di masyarakat.

\section{DAFTAR PUSTAKA}

Abdillah, W., dan J. Hartono. 2015. Partial Least Square (PLS). Penerbit Andi. Yogyakarta.

Arnold, M. J., \& Reynolds, K. E. (2003). Hedonic shopping motivations. Journal of Retailing, 79(2), 77-95. https://doi.org/10.1016/S00224359(03)00007-1

Churchill, G. A. (2005). Dasar-dasar riset pemasaran Jilid 1 Ed.4. Jakarta: Erlangga.

Douglas J. Tigert, Lawrence J. Ring, and Charles W. King (1976) ,"Fashion Involvement and Buying Behavior: a Methodological Study", in NA Advances in Consumer Research Volume 03, eds. Beverlee B. Anderson, Cincinnati, OH: Association for Consumer Research, Pages: 4652.

Edwin Japarianto dan Sugiono Sugiharto. "Pengaruh Shopping Life Style Dan Fashion Involvement Terhadap Impulse Buying Behavior Masyarakat High Income Surabaya" Jurnal Manajemen Pemasaran, Vol. 6, No. 1, April 2011

Engel, James F., R. D. Blackwell, \& P. W. Miniard. (1995). Perilaku konsumen. Jilid 1 (Edisi ke enam). Jakarta : Binarupa Aksara

Geoff Bayley, Clive Nancarrow, (1998) "Impulse purchasing: a qualitative exploration of the phenomenon", Qualitative Market Research: An International Journal, Vol. 1 Issue: 2, pp. 99114, https://doi.org/10.1108/13522759810214271.

Goldsmith, R. E., \& Emmert, J. (1991).Measuring product category involvement: A multitrait-multimethod study. Journal of Business Research, 23(4), 363-371. http://dx.doi.org/10.1016/01482963(91)90021-O

Han, Y. K., Morgan, G. A., Kotsiopulos, A. and Kang, P. J. (1991), "Impulse buying behaviour of apparel purchases", Clothing and Textile Research Journal, Vol.9 No. 3, pp. 15-21.

Hausman, A. (2000). Journal of Consumer Marketing impulse buying behavior A multi-method inves- tigation of consumer motivations in impulse buying behavior. Journal of Consumer Marketing, 17(5), 403-426.

Holbrook, M. B., \& Hirschman, E. C. (1982). The Experiential Aspects of Consumption: Consumer Fantasies, Feelings, and Fun. Journal of Consumer Research, 9(2), 132. https://doi.org/ 10.1086/208906

Liapati, G., Assiouras, I., \& Decaudin, J. M. (2015). The role of fashion involvement, brand love and hedonic consumption tendency in fashion impulse purchasing. Journal of Global Fashion Marketing, 6(4), 251-264. https://doi.org/10.1080/ 20932685.2015.1070679

MacInnis, D.J. dan Price, L.L. (1987), "The role of imagery in information processing review and extensions", Journal of Consumer Research.

Markin, Rom J., Charles M. Lillis, and Chem L. Narayana, (1976), "Social-Psychological Significance of Store Space," Journal of Retailing, 52 (Spring) 43-54.

O'Cass, A. (2000). An assessment of consumers product, purchase decision, advertising and consumption involvement in fashion clothing. Journal of Economic Psychology, 21(5), 545576. https://doi.org/10.1016/S0167-4870(00) 0008-0

O'Cass, A. (2004). Fashion clothing consumption: antecedents and consequences of fashion clothing involvement. European Journal of Marketing, 38(7), 869-882. https://doi.org/10.1108/ 03090560410539294

Parasuraman, A. (1991). Marketing research 2nd ed. Reading, Massachusetts: Addison-Wesley $\mathrm{Pu}-$ blishing Company.

Park, E. J., Kim, E. Y., \& Forney, J. C. (2006). A structural model of fashion-oriented impulse buying behavior. Journal of Fashion Marketing and Management, 10(4), 433-446. https://doi. org/10.1108/13612020610701965

Rook, D.W. (1987), “The Buying Impulse,” Journal of Consumer Research, Vol. 14, pp. 189-199.

Rook, D.W. and S.J. Hoch (1985), Consuming impulses, Advances in Consumer Research, Vol. 12, pp. 23-27

Virvilaite, R., \& Saladiene, V. (2012).Models investigation of factors affecting consumer impulsive purchase behaviour in retail environment.Economics and Management, 17(2), 121-132

Wahdi, M. (2011). Riset pemasaran: teori dan aplikasi untuk pengambilan keputusan cet. 1. Jakarta: Caps (Center for Academic Publishing Service). 